\title{
Las claves hermenéuticas del libro de Antonio Bentué. En qué Creen los que Creen
}

El miércoles 25 de abril de 2018, Antonio Bentué presentó en nuestra Facultad los criterios hermenéuticos con los que lee el Credo y los dogmas católicos en su libro En qué creen los que creen (Barcelona-Buenos Aires, Claret, 2004; ISBN: 84-8297-723-7). La ocasión que se gestó gracias a un anónimo participante de sus catequesis para adultos que quiso generosamente comprar todos los ejemplares que quedaban en la editorial para que se difundiera su perspectiva teológica. En respuesta a tan noble iniciativa, el autor, junto con obsequiar una copia del libro, expuso los aspectos esenciales del mismo, de manera de facilitar su lectura.

En este contexto de gratuidad, el emérito profesor de Teología Fundamental aprovechó de recordarnos que la teología consiste en una mediación entre la experiencia religiosa que la inspira y una determinada matriz cultural, por lo que la tarea de examinar la racionalidad del significado de sus postulados fundamentales es a la vez irrenunciable y siempre vigente. Por con- siguiente, nos invita a transitar por un camino que evita los extremos del fideísmo y del racionalismo, subrayando lo irrenunciable de la razón en la experiencia de fe, en tanto que antídoto frente al egocentrismo antropológico.

En efecto, con una lucidez maduradas en la unión entre una vasta experiencia académica y una comprometida vivencia de la fe, Bentué planteó con notable sencillez y profundad la cuestión de fondo: se trata de indagar en "el sentido razonable de estas verdades eclesiales para una persona adulta del siglo XXI que quiere mantenerse honestamente creyente, sin dejar de ser también intelectualmente honesto" (p.190).

La perplejidad que experimenta el creyente adulto en nuestro tiempo tiene un doble origen. El primero es externo al sistema religioso y tiene que ver con el proceso cultural desplegado en Occidente durante los últimos siglos. Este se inicia con la justa autonomía de la razón conquistada en la modernidad y va hasta la evidencia de fra- 
caso del proyecto de la utopía moderna, decepción de la que surge la oferta de un presente fugaz, característico de la postmodernidad. Este devenir conforma un entorno cultural que se ha vuelto miope ante los problemas de sentido, por lo que las condiciones ambientales no son las más adecuadas para dar razón del sentido de lo que se cree.

El segundo es interno, ya que tiene relación con una determinada conducción de la Iglesia Católica. El impulso dado por el Concilio Vaticano II invita a acoger los cuestionamientos razonables provenientes de la razón moderna. Sin embargo, en el seno de la comunidad eclesial se producen tensiones entre fuerzas contrapuestas que, por una parte, buscan conservar con fidelidad el depósito de la fe aferrándose al literalismo de las formulaciones y, por otra, fuerzas que asumen el riesgo de entrar en contacto con las sensibilidades culturales contemporáneas. Se trata, en fin, de la actitud que debe tomar la Iglesia ante el mundo, se debate entre una clausura sectaria o una apertura misionera.

En consecuencia, el doctor en Ciencias de la Religión señaló las dos claves con las que nos invita a leer los postulados esenciales de nuestra fe, de manera que sea posible llevar adelante una labor mi- sionera de cara al mundo. En primer lugar, la Palabra de Dios antes que informar quiere salvar. Es por esto que es legítimo hacer una recepción crítica de la interpretación tradicional que se ha hecho de esta Palabra y preguntarse por el sentido que puede tener hoy.

En segundo lugar, evocando el No 170 del Catecismo, recordó que lo único absoluto es la realidad misma de Dios, y por lo tanto, las formulaciones teológicas son tan solo mediaciones necesarias y por lo mismo proyecciones condicionadas. El lenguaje teológico es eminentemente análogo, en una relación en que es mayor la desemejanza que la semejanza con respecto a la realidad que se quiere significar. En consecuencia, es preciso asumir en toda su radicalidad la jerarquía de verdades que sugiere profundizar lo esencial y relativizar lo secundario, de manera que la misión esté libre de motivaciones egocéntricas que buscan comodidades o ventajas.

Finalmente, estas claves de lectura nos dirigen inevitablemente hacia el compromiso social, en el cual se alcanza el núcleo de sentido del contenido de nuestra fe: "el contenido de todas las formulaciones teológicas es "relativo» a lo único absoluto en la experiencia creyente y humana, que es la de- 
cisión relacional para con el otro, de profesión, sino a toda persona única que pone en sintonía con lo que quiera vivir una fe madura e que Dios es" (p.261). Así, el funda- intelectualmente honesta, lo que mento trinitario nos revela que el está en juego es la racionalidad de carácter relacional es el contenido la propia opción creyente. de nuestra confesión de fe.

Esta obra propone en una forma clara y atractiva una tarea verdaderamente teológica que no compete únicamente a los teólogos

Juan Pablo Sepúlveda Hernaiz CMagister Facultad de Teología Pontificia Universidad Católica de Chile 